\title{
DISTRIBUIÇÃO ESPACIAL DOS INDIVÍDUOS EM TRÊS POPULAÇÕES DE Dipteryx alata Vogel COM BASE EM CARACTERES MORFOLÓGICOS
}

\author{
Daniela Silvia de Oliveira Canuto ${ }^{1}$, Alexandre Marques da Silva², Mario Luiz \\ Teixeira de Moraes ${ }^{3}$, Ananda Virginia de Aguiar ${ }^{4}$
}

\begin{abstract}
${ }^{1}$ Pós-doutoranda, Departamento de Fitotecnia, Tecnologia de Alimentos e Sócio Economia da Faculdade Engenharia / UNESP Campus de Itha Solteira. ${ }^{2}$ Geógrafo, Mestre e Técnico Agropecuário do Departamento de Fitotecnia, Tecnologia de Alimentos e Sócio Economia da Faculdade Engenharia / UNESP Campus de llha Solteira. ${ }^{3}$ Docente do Departamento de Fitotecnia, Tecnologia de Alimentos e Sócio Economia da Faculdade Engenharia / UNESP Campus de llha Solteira. ${ }^{4}$ Pesquisadora da Embrapa Floresta.
\end{abstract}

RESUMO: O reconhecimento da existência de estruturação espacial nas populações naturais auxilia no estabelecimento de medidas de conservação genética, indicando formas de maximizar a diversidade genética na coleta de sementes. Desta maneira, este trabalho teve como objetivo avaliar o padrão de distribuição espacial em três populações naturais de Dipteryx alata, com base nos caracteres morfológicos altura e diâmetro a altura do peito (DAP). As populações naturais localizam-se em Campina Verde (MG), Itarumã (GO) e Brasilândia (MS), onde as árvores foram identificadas, medidas e georreferenciadas. A análise da distribuição espacial foi realizada a partir da estimativa do Índice de Moran. Concluiu-se que as populações apresentam estruturação espacial fraca, sendo recomendadas para formação de populações base para programas de melhoramento e conservação ex situe in situ.

Palavras-chave: cumbaru, baru, cumaru, Índice de Moran, estruturação espacial.

\section{SPATIAL DISTRIBUTION OF MORPHOLOGICAL CHARACTERS IN NATURAL POPULATIONS OF THREE Dipteryx alata Vogel}

\begin{abstract}
The recognition of spatial structure in natural populations helps in the establishment of conservation genetics, indicating ways to maximize the genetic diversity in seed collection. Thus, this study aimed to evaluate the spatial distribution pattern in three natural populations of Dipteryx alata, based on morphological characters height and diameter at breast height (DBH). The natural populations are located in Campina Verde (MG), Itarumã (GO) and Brasilândia (MS), where the trees were identified, measured and georeferenced. The spatial distribution were performed based on an estimate of the Moran Index. It was concluded that the populations have weakspatial structure, and these populations recommended for the formation of base populations for breeding programs and conservation in situ and ex situ.
\end{abstract}

Key words: cumbaru, baru, cumaru, Moran Index, spatial structure.

\section{INTRODUÇÃO}

A caracterização da distribuição espacial dos indivíduos de uma população é fundamental par o entendimento da Estrutura Genética Espacial. Assim, o reconhecimento da existência de certo nível de estruturação genética espacial nas populações da espécie auxilia no estabelecimento de medidas de conservação genética, indicando formas de maximizar a diversidade genética na coleta de sementes para programas conservação ex 
situ, melhoramento genético, recuperação de áreas degradadas, bem como inferir sobre tamanhos mínimos de área para a sua conservação in situ (GUSSON et al., 2005). Tais estudos são indicados para espécies que apresentam potencial econômico e seu habitat esteja sendo fragmentado, como é o caso da Dipteryx alata, que é uma espécie arbórea da familia Fabaceae, amplamente distribuída no bioma Cerrado, com possibilidade de utilização na alimentação humana e animal, medicamentos industriais e madeira para construção (ALMEIDA et al., 1998).

A autocorrelação espacial pode ser definida como propriedade de variáveis assumirem valores, em pares de localidades separadas por uma distância, mais similares (autocorrelação positiva) ou menos similares (autocorrelação negativa) do que seria esperado pela associação aleatória dos pares observados (LEGENDRE, 1993), citado por Giudice Neto (1999).

Entre as variáveis às quais a análise de autocorrelação pode ser útil estão a variação geográfica de caracteres morfológicos, as frequências gênicas, os padrões de distribuição dos genes ou ainda a abundância de espécies (SOKAL e ODEN, 1978). Mais conhecido ainda são os diversos modelos de estrutura populacional no espaço, relacionados principalmente à conectividade para fluxo gênico entre os genes e sua importância para manter a integridade genética das espécies (WRIGTH, 1931). Sendo assim, o objetivo deste trabalho foi avaliar o padrão de distribuição espacial em três populações de Dipteryx alata, com base nos caracteres morfológicos altura e diâmetro a altura do peito.

\section{MATERIALEMÉTODOS}

As populações de Dipteryx alata avaliadas localizam-se em três Estados diferentes: Minas Gerais (Campina Verde), Goiás (Itarumã) e Mato Grosso do Sul (Brasilândia). Nessas populações foram identificadas árvores matrizes e georreferencidas por meio de GPS (Global
Positioning System), aparelho da marca Garmim, modelo GPSMAP 60CSx, a partir do qual foram obtidos o posicionamento considerando o Datum SAD 69, com precisão entre 0 a $10 \mathrm{~m}$.

O número de indivíduos por população foi de $26 \mathrm{em}$ Itarumã, 41 em Brasilândia e 48 em Campina Verde. Foram mensurados os caracteres: altura em metros, obtida por um hipsometro Vertex IV; diâmetro a altura do peito em centímetros - DAP, que consiste na medida a 1,30 $\mathrm{m}$ acima do solo, obtido por meio de fita métrica, cujo valor foi dividido por $3,1415(\pi)$

A análise de autocorrelação espacial é um conjunto de procedimentos estatísticos delineados para detectar e quantificar a dependência em uma variável (altura e DAP) baseada em valores amostrados de localidades múltiplas mapeadas em um espaço geográfico (coordenadas geográficas).

A análise da distribuição espacial das árvores (matrizes) em cada uma das populações de $D$. alata foram realizadas a partir da estimativa do Índice de Moran, com base em Sokal e Oden (1978a, b). Para esta análise foi utilizado o programa SAAP 4.3 (Spatial Autocorrelation Analysis Program), descrito por Wartenberg (1989).

Aanálise de autocorrelação considera cada caráter $\left(p_{i}\right)$ como uma variável. Assim, pares de indivíduos amostrados classificamse de acordo com a distância Euclidiana $d_{i j}$, sendo que a classe $k$ inclui $d_{i j}$, satisfazendo $k-1<d_{i j}<k$, em que $k$ vai de 1 a 4 . O Índice de Moran $(\hat{I})$ para classe $k$ foi calculado pela expressão:

$$
\hat{I}=n \uparrow \sum_{j} w_{i j} Z_{i} Z_{j} / w \sum_{i} Z_{i}^{2}
$$

em que : $=\bar{p}_{i}-\bar{p}$, sendo Jాa média de $\overline{p_{\Downarrow}}, w_{i j}=$ 1 se a distância entre a i-ésima e a j-ésima árvore for classificada dentro da classe $k$; do contrário, $w_{i j}$ é zero e $n$ é o número total de amostras.

0 Indice de Moran pode assumir valores entre -1 e +1 , em que -1 significa que os indivíduos pareados mais distantes são semelhantes (autocorrelação negativa) e +1 
significa que os indivíduos mais próximos são idênticos (autocorrelação positiva) (SOKAL e ODEN, 1978a, b). O valor zero significa ausência de autocorrelação, isto é, os indivíduos estão aleatoriamente distribuidos no espaço.

\section{RESULTADOSEDISCUSSÃO}

A distribuição espacial é apresentada por meio de correlogramas plotados em função dos valores dos Indices de Moran e das classes de distâncias, para as três populações de Dipteryx alata (Figura 1). O correlograma indica a extensão da estrutura espacial, sendo que quando esta ocorre, a sua significância é avaliada pelo Teste de Bonferroni.

Conforme o critério de Bonferroni o correlograma da população de MG expressa padrão espacial significativo para DAP $(P \leq$ $0,001)$ e para altura $(P \leq 0,01)$; na população de GO não houve significância para ambos caracteres; e na população de MS o padrão espacial é significativo a $1 \%$ para DAP e $5 \%$ para altura. O padrão espacial das populações de Dipteryx alata estudadas foram fracos, sendo o maior valor encontrado na população de MG na terceira classe de distância $(-0,22)$ para DAP. Ao contrário de Soares et al. (2008), que encontraram padrōes espaciais demasiadamente fortes em populações de Dipteryx alata, o que explica que menor niveis de fluxo gênico pode ser encontrado em função de entraves causados por impactos antropogênicos.

O correlograma do Índice de Moran da população de MG apresenta valores significativos e positivos na primeira classe para os dois caracteres $(0,11$ para altura $e$ 0,14 para DAP), e na quarta classe para o caráter altura $(0,15)$. Segundo Diniz Filho (1997), a autocorrelação (distribuição espacial) positiva em uma dada classe de distância estimado pelo índice de Moran, indica que as árvores situadas a essa distância tendem a ser parecidas entre si para a variável estudada, em relação à variação total existente. Para Sebbenn (1997), a existência da estrutura genética espacial positiva, isto é, de indivíduos geneticamente correlacionados (aparentados), localizados próximos dentro das populações, pode ser indicativo da ocorrência de cruzamentos endogâmicos. Tarazzi et al. (2010), avaliando progênies de Dipteryx alata por meio de marcadores moleculares, encontraram evidencias de pólen com dispersão de longa distância, sugerindo que o principal fator de estruturação das populações é restrito a dispersão de sementes.

A auto correlação negativa na população de Campina Verde - MG ocorreu na segunda classe para altura $(-0,19)$, na terceira classe para o DAP $(-0,02)$ e quinta classe para altura $(-0,11)$. Mudança de valores significativos positivos para negativos em classe posterior indica que são compativeis a gradientes circulares, que provavelmente as árvores são de mesma entidade reprodutiva e em distâncias maiores ocorre a presença de mães e filhos, ou seja, sobreposição de geração. Por este padrão se repetir para o caráter altura aparentemente pode estar formando subpopulações.

O correlograma da população GO apresentou valor significativo e negativo apenas na primeira classe e para o caráter altura. Esse fato indica que as árvores localizadas na distância de $483 \mathrm{~m}$ tendem a ser diferentes em altura e essa diferença pode estar relacionada a fatores ecológicos como competição por luz. Também plantas próximas podem ser descendentes das árvores maiores tendo assim idades e consequentemente alturas diferentes.

Com base no caráter DAP, a distribuição espacial ocorre de forma aleatória, levando em consideração que o agregamento genético espacial é determinado pelos mecanismos de dispersão de pólen e sementes (GUSSON et al., 2005). Pode-se inferir que a dispersão do pólen em Dipteryx alata, realizada por vários insetos, foram eficientes para bom fluxo gênico, e as sementes dispersas por animais (MACEDO et al., 2000) em grandes distâncias permitiram a distribuição aleatória espacial, onde indivíduos próximos não são semelhantes entre si. Em várias espécies também não foi encontrado padrão espacial, como Genipa 
americana (SEBBENN et al., 1998), Marchaerium villosum (GIUDICE NETO, 1999), Myracrodruon urundeuva (LACERDAe KAGEYAMA, 2003), Ocotea odorifera (KAGEYAMA et al., 2003), Astronium fraxinifolium (AGUIAR et al., 2004) e Caryocar brasiliense (SILVA et al., 2005). Com base nos caracteres silviculturais avaliados, as populações estudadas por esses autores não apresentaram um padrão espacial, sendo assim, para fins de conservação ex situ, a amostragem nessas populações pode ser realizada aleatoriamente.

O padrão espacial da população MS reflete distribuição espacial positiva no menor intervalo de distância, passando para negativo nos intervalos maiores. O valor positivo na primeira classe indica que as árvores situadas de 0 a $275 \mathrm{~m}$ tendem a ser parecidas para altura e DAP, na segunda classe, O DAP apresenta valores negativos, que indica um processo de diferenciação nesta distância. Nas demais classes de distâncias a distribuição espacial dos caracteres avaliados é aleatória, portanto para essa população, é recomendado a coleta de sementes de árvores distantes estre si a partir de $501 \mathrm{~m}$, para um eventual programa de melhoramento genético, por apresentarem uma base genética ampla para os caracteres altura e DAP.
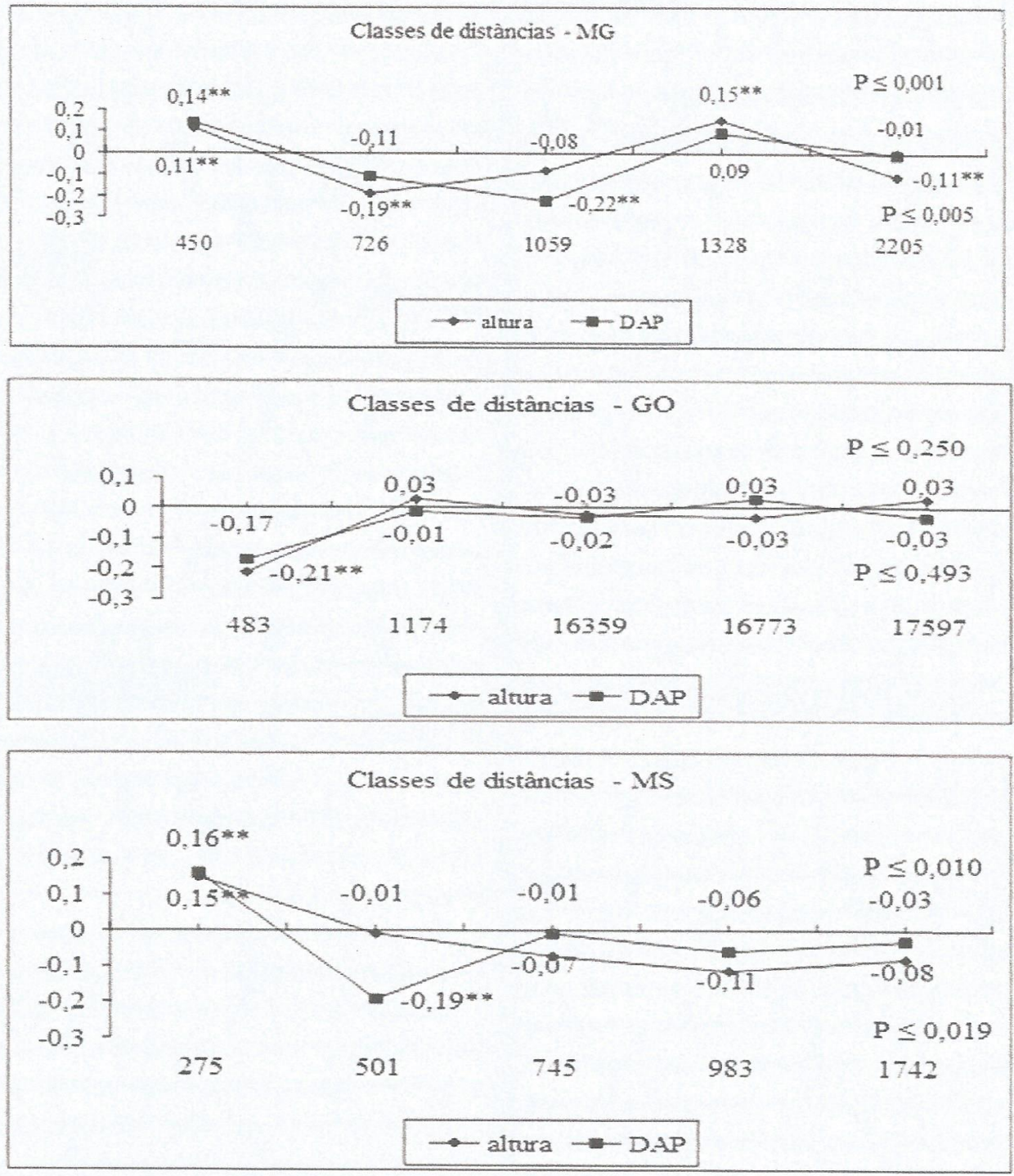

P: Significância total do correlograma (aproximação de Bonferroni); **: $P<0,01 ;$ * $P<0,05$.

Figura 1. Correlograma espacial dos caracteres morfológicos do Índice de Moran para as cinco classes de distância nas populações de Dipteryx alata estudadas. 


\section{CONCLUSÕES}

As populações de Dipteryx alata avaliadas apresentam estruturação espacial fraca, o que permite recomendar estas populações para programas de melhoramento genético e conservação ex situ e in situ. No entanto, a coleta de sementes deve ser realizada em árvores distantes entre si.

\section{REFERÊNCIAS}

AGUIAR, A. V.; COELHO, A. S. G.; MOURA, M. F.; MORAIS, L. K.; PINHEIRO, J. B.; MORAES, M. L.; ZUCCHI, M. I.; MOURA, N.F.; VENCOVSKY, R. Autocorrelação espacial de caracteres morfológicos em populações naturais de gonçalo-alves (Astronium fraxinifolium Schott.). Bioscience journal, Uberlandia, v. 20, n. 1; p.151-160, 2004.

ALMEIDA, S. P.; PROENÇA, C. E. B.; SANO, S. M.; RIBEIRO, J. F. Cerrado: espécies vegetais úteis. Planaltina: EMBRAPA-CPAC, 1998. $464 \mathrm{p}$.

DINIZ FILHO, J. A. F. Análise de autocorrelação espacial interferência microevolutiva e aplicações em genéticas de populações. Ribeirão Preto: Sociedade Brasileira de genética, p. 82-145, 1997. (Série monografia, n.6).

GIUDICE NETO, J. D. Estrutura genética por isoenzimas em populaçōes naturais de jacarandá paulista (Marchaerium villosum Vog.). 1999. 128 f. Dissertação (Mestrado em Recursos Florestais) - Escola Superior de Agricultura "Luiz de Queiroz", Universidade de São Paulo, Piracicaba, 1999.

GUSSON, E.; SEBBENN, A. M.; KAGEYAMA, P. Y. Diversidade e estrutura genética espacial em duas populações de Eschweilera ovata. Scientia Forestalis, Piracicaba, n. 67, p.123135, 2005.

KAGEYAMA, P. Y.; CUNHA, G. C.; BARRETO, K. D.; GANDARA, F. B.; CAMARGO, F. R. A.; SEBBENN, A. M. Diversidade e autocorrelação genética espacial em populações de Ocotea odorifera (Lauraceae). Scientia Forestalis, Piracicaba, n. 64, p.108119, 2003.

LACERDA, C. M. B.; KAGEYAMA, P. Y. Estrutura genética espacial de duas populações naturais de Myracrodruon urundeuva M. Allemão na região semi-árida, Brasil. Revista Árvore, Viçosa, v. 27, n. 2, p.145-150, 2003.

MACEDO, M.; FERREIRA, A. R.; SILVA, C. J. Estudos da dispersão de cinco espécieschave em um capão no Pantanal de Poconé, Mato Grosso. In: SIMPÓSIO SOBRE RECURSOS NATURAIS E SÓCIOECONÔMICOS DO PANTANAL, 3., 2000, Corumbá. Anais... Corumbá: EMBRAPACPAP, 2000. 14 p. Disponivel em: <file://ID:/Documents/pendrive\%20de\%20rab inho/Pos\%20Doc\%202011/Cultura\%20agron omica/MACEDO-051.pdf>. Acesso em: 23 jun. 2014.

SEBBENN, A. M. Estrutura genética de subpopulação de Genipa americana L. (Rubiaceae) a partir de isoenzimas. 1997. 107 f. Dissertação (Mestrado em Ciências Florestais) - Escola Superior de Agricultura "Luiz de Queiroz", Universidade de São Paulo, Piracicaba, 1997.

SEBBEN, A. M.; KAGEYAMA, P. Y.; VENCOVSKY, R. Variabilidade genética, sistema reprodutivo e estrutura genética espacial em Genipa americana L. através de marcadores isoenzimáticos. Scientia Forestalis, Piracicaba, n. 53, p.15-30, 1998.

SILVA, A. M.; CANUTO, D. S. O.; AGUIAR, A. V.; MORAES, M. L. T. Autocorrelação espacial em uma população natural de piqui (Caryocar brasiliense Camb.) em área degradada. ENCONTRO DE GEÓGRAFOS DAAMÉRICA LATINA, 10., 2005, São Paulo. Anais... São Paulo: GEOUSP, 2005. p. 14233-14243. 1 CD-ROM.

SOARES, T. N.; CHAVES, L. J.; TELLES, M.P. 
C.; DINIZ-FILHO, J. A. F.; RESENDE, L. V. Landscape consevation genetics of Dipteyx alata ("baru" tree: Facbaceae) from Cerrado region of central Brazil. Genetica, Gravenhage, v. 132, p.9-19, 2008.

SOKAL, R. R.; ODEN, N. L. Spatial autocorrelation in biology 1 Metodology. Biological Journal of the Linnean Society of London, London, v. 10, p.199-228, 1978a.

SOKAL, R. R.; ODEN, N. L. Spatial autocorrelation in biology 2 some biological implications and four applications of evolutionary and ecological interest. Biological Journal of the Linnean Society of London, London, v. 10, p.229-249, 1978 b.

TARAZI, R.; MORENO, M.A.; GANDAR, F. B.; FERRAZ, E. M.; MORAES, M. L. T.; VISON, C. C.; CIAMPI, A. Y.; VENCOVSKY, R; KAGEYAMA, P. Y. High levels of genetic differentiation and selfing in the Braziliam cerrado fruit tree Dipteryx alata Vog. (Fabaceae). Genetics and Molecular Biology, Ribeirão Preto, v. 33, n. 1, p.78-85, 2010.

WARTENBERG, D. SAAP: Spatial autocorrelation analysis program. New York: Exeter publishers. 1989.31 p.

WRIGTH, S. Evolution en Mendelian populations. Genetics, Austin, v. 16, p.97-159, 1931. 